\title{
ÉPOCA DE APLICAÇÃO DE NITROGÊNIO NO MILHO CULTIVADO EM SUCESSÃO À AVEIA PRETA NO SISTEMA PLANTIO DIRETO
}

\author{
TIME OF NITROGEN APPLICATION IN NO-TILLAGE CORN CROP \\ PLANTED OVER BLACK OATS
}

\author{
Volnei Pauletti ${ }^{1}$ Luiz Carlos Costa ${ }^{2}$
}

RESUMO

Este trabalho teve como objetivo avaliar o efeito de épocas de aplicação de $N$ sobre parâmetros de rendimento de milho, cultivado em sucessão à aveia preta em plantio direto. Os experimentos foram conduzidos no ano agrícola de 1996/97 em três campos demonstrativos e experimentais pertencentes à Fundação ABC, nos Campos Gerais do Paraná. O delineamento experimental foi de blocos ao acaso com parcelas subdivididas, sendo nas parcelas a adubação na aveia $\left(\mathrm{O}\right.$ e $30 \mathrm{~kg} \mathrm{há}{ }^{-1}$ de $\mathrm{N} \mathrm{na}$ semeadura) e nas subparcelas, as épocas de aplicação do $\mathrm{N}$ no milho (sem N: $30 \mathrm{~kg} \mathrm{há-1} \mathrm{na} \mathrm{semeadura} \mathrm{+} \mathrm{90kg} \mathrm{há-l} \mathrm{em} \mathrm{cobertura}$ na $6^{\circ}$ folha: $90 \mathrm{~kg} \mathrm{ha}^{-1}$ no manejo da aveia $+30 \mathrm{~kg} \mathrm{ha}^{-1} \mathrm{na}$ semeadura e; J20kg há-1 no manejo da aveia + 30kg há ${ }^{-1}$ na semeadura). Verificou-se que a adubação da aveia não influenciou o rendimento do milho. $O$ rendimento de grãos de milho não foi afetado pela aplicação antecipada do $\mathrm{N}$, normalmente utilizado em cobertura no milho.

Palavras-chave: nitrogênio, plantio direto, milho, época de aplicação.

\section{SUMMARY}

This paper has as main goal the evaluation of the effect of nitrogen application on the yield of no tillage com crop, planted over black oats. Experiments were conducted $m$ the agricultural year of 1996/97 in three experimental units of the $A B C$ Foundation located in the Campos Gerais Region of the state of Paraná. The experimental design was a split-plot randomized block, being the plot treatments the two doses of $N$ applied to the oats crop (O and $30 \mathrm{~kg} \mathrm{ha}^{-1}$ in the planting time) as the main plots and as the time of application of $N$ in the com crop (no nitrogen; $30 \mathrm{~kg} \mathrm{há}{ }^{-1}$ in the planting plus $90 \mathrm{~kg} h^{-1}$

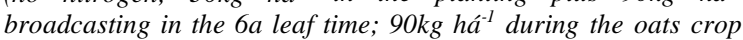

\begin{abstract}
management plus $30 \mathrm{~kg} \mathrm{há} a^{-1}$ in the com planting; and $120 \mathrm{~kg} \mathrm{há}^{-1}$ during the oats crop management plus $30 \mathrm{~kg} \mathrm{há}^{-1}$ in the com planting) as split plot treatments. It was verified the oats crop fertilization dia not influenced com yield. The com yield was not affected by anticipated $N$ application usually used in corn's broadcasting.
\end{abstract}

Key words: nitrogen, no tillage crop, com, application timing.

\section{INTRODUÇÃO}

O nitrogênio $(\mathrm{N})$ é o nutriente mais exigido pela cultura do milho, sendo necessários, em média, 23,8kg de $\mathrm{N}$ para cada tonelada de grãos. As doses de $\mathrm{N}$ recomendadas para suprir essa demanda variam em função, especialmente, do ambiente e rotação de culturas (KANTHACK, 1991; AITA $\boldsymbol{e t}$ al., 1994; SANGOI \& ALMEIDA, 1994).

Quando o sistema plantio direto é adotado, uma das primeiras alterações que ocorrem em relação ao sistema convencional é a manutenção dos restos culturais sobre a superfície do solo. Com isso, toda a dinâmica dos nutrientes é alterada, inclusive a do $\mathrm{N}$, especialmente pelo aumento da matéria orgânica (M.O.) do solo (MACHADO, 1976; PARRA, 1984; SÁ, 1993) e manutenção da cobertura morta com consequente aumento da atividade biológica (CATTELAN \& VIDOR, 1990; BALLOTA et al., 1996).

\footnotetext{
${ }^{1}$ Engenheiro Agrônomo, Coordenador da Área de Fertilidade de Solos, Fundação ABC, 84166-990, Castro - Paraná. E-mail: fabc@fundacaoabc.com.br. Autor para correspondência.

${ }^{2}$ Técnico Agrícola, Área de Fertilidade de Solos, Fundação ABC. 
Em plantio direto, na Região dos Campos Gerais, a aplicação de 90 a $120 \mathrm{~kg} \mathrm{há}^{-1}$ de $\mathrm{N}$ em milho cultivado sobre aveia e 45 a $75 \mathrm{~kg}$ há $^{-1}$ de $\mathrm{N}$ em milho cultivado sobre leguminosa seriam suficientes para a obtenção dos maiores retornos económicos, mantendo-se uma aplicação de $30 \mathrm{~kg} \mathrm{há}^{-1}$ na semeadura, e o restante em uma única aplicação entre a $6^{\mathrm{a}}$ e $8^{\mathrm{a}}$ folha expandida, utilizando como fonte a ureia (SÁ, 1995).

No ano agrícola de 1995/96, SÁ (1996) observou que a aplicação do N no florescimento da aveia, ou seja, no momento do manejo dessa cultura para a posterior semeadura direta do milho, proporcionou rendimentos iguais à aplicação na 6" folha, em áreas há mais de seis anos sob plantio direto, atribuindo grande parte do sucesso dessa técnica à atividade biológica. Portanto, com a introdução do plantio direto e o aumento da atividade biológica, visualiza-se a flexibilização do período de aplicação do $\mathrm{N}$ em cobertura para o milho.

Com o objetivo de avaliar o efeito de épocas de aplicação do $\mathrm{N}$ sobre parâmetros de rendimento de milho, cultivado em sucessão à aveia preta, sob plantio direto, desenvolveram-se trabalhos em áreas experimentais pertencentes à Fundação ABC, no Paraná, no ano agrícola de 1996/97.

\section{MATERIAL E MÉTODOS}

Os experimentos foram conduzidos no ano agrícola de 1996/97, nos Campos Demonstrativos Experimentais pertencentes à Fundação ABC, nos municípios de Castro (há oito anos com plantio direto - PD), Ponta Grossa (há nove anos com PD) e Arapoti (há sete anos com PD). As análises de solo iniciais são apresentadas na tabela 1. As rotações de culturas utilizadas anteriormente à instalação dos experimentos foram aveia/soja/aveia/soja, em Arapoti e Castro, e aveia/soja/trigo/soja em Ponta Grossa.

O delineamento experimental adotado foi em blocos ao acaso, em parcelas subdivididas, com quatro repetições, sendo nas parcelas as doses de $\mathrm{N}$ no sulco de semeadura da aveia $\left(\mathrm{O}\right.$ e $30 \mathrm{~kg}$ há $\left.^{-1}\right)$ e, nas subparcelas, as épocas de aplicação do $\mathrm{N}$ no milho (sem N; $30 \mathrm{~kg} \mathrm{há}^{-1}$ no sulco de semeadura do milho $+90 \mathrm{~kg}$ há-1 em cobertura na $6^{\mathrm{a}}$ folha do milho; $90 \mathrm{~kg}$ há $^{-1}$ no manejo da aveia, ou seja, no pleno florescimento $+30 \mathrm{~kg}$ há $^{-1}$ no sulco de semeadura do milho e; $120 \mathrm{~kg}$ há $^{-1}$ no manejo da aveia $+30 \mathrm{~kg} \mathrm{há}^{-1}$ no sulco de semeadura do milho).

Os cultivares utilizados foram o Pioneer 3099 (Ponta Grossa), Zeneca 8392 (Castro) e
Tabela 1 - Análises de solo das áreas antes da implantação dos experimentos.

\begin{tabular}{|c|c|c|c|c|c|c|c|c|}
\hline Prof. & $\mathrm{pH}$ & $\mathrm{P}^{1}$ & $\mathrm{MO}^{2}$ & $\mathbf{K}$ & $\mathrm{Ca}$ & $\mathrm{Mg}$ & $\mathrm{V}$ & Argila \\
\hline $\mathrm{cm}$ & $\mathrm{CaCl}_{2}$ & $\mathrm{mg} / \mathrm{dm}^{3}$ & $\mathrm{~g} / \mathrm{dm}^{3}$ & \multicolumn{3}{|c|}{$\mathrm{mmolc} / \mathrm{dm}^{3}$} & $\%$ & $\%$ \\
\hline \multicolumn{9}{|c|}{ Arapoti } \\
\hline $0-5$ & 5.7 & 19 & 28 & 1.8 & 19 & 10 & 39.8 & 10 \\
\hline $5-10$ & 5.7 & 10 & 21 & 0.7 & 18 & 11 & 39.4 & 19 \\
\hline $10-20$ & 5.7 & 8 & 18 & 0.3 & 18 & 10 & 39.5 & 22 \\
\hline $20-30$ & 5.8 & 5 & 18 & 0.3 & 14 & 9 & 35.5 & 22 \\
\hline \multicolumn{9}{|c|}{ Ponta Grossa } \\
\hline $0-5$ & 5.5 & 64 & 51 & 4.2 & 67 & 33 & 74,3 & 46 \\
\hline $5-10$ & 5.7 & 50 & 41 & 2.9 & 46 & 25 & 64,5 & 48 \\
\hline $10-20$ & 5.6 & 24 & 36 & 2.2 & 2.3 & 15 & 46,5 & 49 \\
\hline $20-30$ & 5.5 & 7 & 32 & 1.8 & 1.4 & 11 & 33,8 & 51 \\
\hline \multicolumn{9}{|c|}{ Castro } \\
\hline $0-5$ & 4.8 & 32 & 67 & 4.6 & 20 & 11 & 29.7 & 24 \\
\hline $5-10$ & 4.6 & 25 & 61 & 61 & 14 & 7 & 19.7 & 23 \\
\hline $10-20$ & 4.7 & 11 & 56 & 1.7 & 14 & 7 & 19.9 & 22 \\
\hline $20-30$ & 4.8 & 5 & 45 & 1.3 & 11 & 7 & 19.3 & 21 \\
\hline
\end{tabular}

${ }^{1}$ Determinado por resina de troca aniônica; ${ }^{2}$ Matéria orgânica.

Pioneer 3063 (Arapoti). A fonte de $\mathrm{N}$ utilizada foi ureia em Castro e Ponta Grossa e sulfato de amónio em Arapoti. Imediatamente após a aplicação da ureia na aveia, foi realizado o manejo mecânico dessa cultura com rolo faca em Castro, e químico, com herbicida e sem rolar, em Ponta Grossa e Arapoti. A adubação utilizada na cultura do milho foi de $60 \mathrm{~kg}$ há ${ }^{-1}$ de $\mathrm{P}_{2} \mathrm{O}_{5}, 60 \mathrm{~kg}$ há ${ }^{-1}$ de $\mathrm{K}_{2} \mathrm{O}$ e $3 \mathrm{~kg}$ há ${ }^{-1}$ de $\mathrm{Zn}$, no sulco de semeadura, em todos os locais.

O tamanho das parcelas foi de 12,5 x $12,5 \mathrm{~m}$. Realizou-se análise da folha índice (primeira folha abaixo e oposta à espiga principal), utilizandose o terço médio das folhas coletadas em vinte plantas por parcela, no pleno florescimento. Colheram-se quatro linhas centrais de cinco metros para determinar o rendimento de grãos. Também foram avaliados a massa de mil grãos (MMG) determinada através da contagem de 250 grãos e correção de sua umidade, extrapolando-se o resultado para 1.000 grãos; grãos ardidos através da avaliação de quantidade de grãos ardidos em 100 grãos para cada parcela colhida; altura de planta obtida em 10 plantas por parcela pela medida da distância entre o nível do solo e o ápice da inflorescência masculina e; altura de espiga obtida da mesma forma que altura de planta, porém, medindo-se até a inserção da espiga principal. 
Os dados foram submetidos à análise de variância e as médias comparadas pelo teste de Tukey em nível de 5\% de probabilidade de erro.

\section{RESULTADOS E DISCUSSÃO}

A aplicação de $\mathrm{N}$ na semeadura da aveia não proporcionou aumento significativo na produtividade do milho em todos os locais, o que indica a necessidade de adubação nitrogenada visando especificamente à cultura do milho. Esses dados discordam dos obtidos por SÁ (1996), que observou aumento no rendimento de grãos de milho com a adubação nitrogenada na aveia.

A aplicação de $\mathrm{N}$ no milho proporcionou aumento significativo de produtividade em relação à testemunha, em todos os locais (Tabela 2), concordando com SANGOI \& ALMEIDA (1994) e ESCOSTEGUY et al. (1997).

Observa-se que em Arapoti (Tabela 2), a aplicação de $\mathrm{N}$ no manejo da aveia $\left(90 \mathrm{~kg}\right.$ há $\left.^{-1}\right)$, apesar de não apresentar rendimento estatisticamente inferior à aplicação em cobertura, mostrou comportamento diferenciado dos demais locais, com uma diferença de $855 \mathrm{~kg}$ há ${ }^{-1}$ em relação à aplicação em cobertura. Nesse local, o desenvolvimento da aveia foi prejudicado em função da falta de chuvas no início do seu desenvolvimento. A utilização de sulfato de amónio, com o objetivo de evitar perdas por volatilização, foi menos importante que a presença da palha na superfície, evidenciando a importância da palha e da atividade biológica na dinâmica do $\mathrm{N}$, como realçam os trabalhos desenvolvidos por IRITANI \& ARNOLD (1960), JANSEN \& KUCEY (1988) e HOLTZ (1995). A textura do solo neste local também pode ter influenciado, devendo-se realizar mais trabalhos para avaliar o seu efeito, apesar de o trabalho desenvolvido por Basso \& Ceretta, apud CERETTA (1997), ter mostrado que a aplicação no manejo da aveia proporcionou maior rendimento que o $\mathrm{N}$ aplicado em cobertura do milho, mesmo em solo com teor de argila de apenas $11 \%$. Em Ponta Grossa e em Castro (Tabela 2), a aplicação antecipada de N apresentou rendimento igual à aplicação em cobertura, concordando com SÁ (1996), que realizou trabalhos na mesma região. Observa-se também que a aplicação antecipada do $\mathrm{N}$ no milho mostrou-se tão eficiente quanto a aplicação após a emergência do milho, independente da forma de manejo da aveia, mecânico com rolo faca em Castro, ou químico com herbicida em Ponta Grossa.

$\mathrm{O}$ aumento da dose de $\mathrm{N}$ aplicada no manejo da aveia também não refletiu em aumento de produtividade do milho, confirmando a dose total de $120 \mathrm{~kg}_{\text {há }}{ }^{-1}$ de $\mathrm{N}$ para o milho como a adequada para a região dos Campos Gerais (SÁ, 1995).
Tabela 2 - Rendimento de grãos de milho em função de épocas de aplicação da adubação nitrogenada na sucessão aveia/milho.

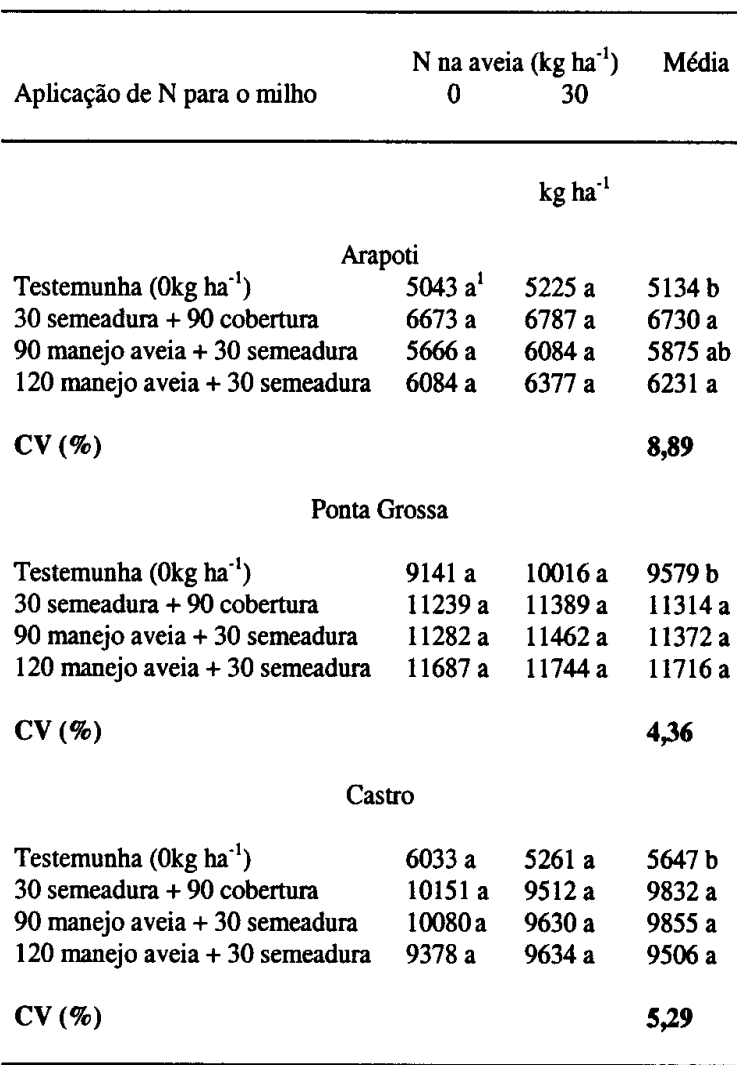

'Valores seguidos da mesma letra na coluna não diferem significativamente pelo teste de Tukey em nível de 5\%.

A aplicação de $\mathrm{N}$ na semeadura da aveia não influenciou a massa de mil grãos em todos os locais. Já a ausência de $\mathrm{N}$ proporcionou os menores valores em Ponta Grossa e Castro (tabela 3), discordando de ESCOSTEGUY et al. (1997), que não observaram diferença entre o tratamento que não recebeu adubação nitrogenada e os que receberam, enquanto em Arapoti (Tabela 3), a aplicação antecipada de $\mathrm{N}$ apresentou valores semelhantes à ausência de N.

As épocas de aplicação de $\mathrm{N}$ no milho também não influenciaram a massa de mil grãos, com exceção de Castro, onde a aplicação de $90 \mathrm{~kg}$ há $^{-1}$ de $\mathrm{N}$ no manejo da aveia proporcionou os maiores valores (Tabela 3). SANGOI \& ALMEIDA (1994), no entanto, observaram correlação linear entre dose de $\mathrm{N}$ e massa de mil grãos, atribuindo tal efeito à manutenção da atividade fotossintética por um maior período, com consequente maior aporte de $\mathrm{N}$ para a cultura. 

comportamento foi bastante diferenciado entre os locais. Isso se deve provavelmente aos elevados coeficientes de variação obtidos.

A altura de planta e espiga foi maior com a aplicação de N em Ponta Grossa (Tabela 3), discordando de SANGOI \& ALMEIDA (1994), que somente observaram efeito de doses de $\mathrm{N}$ sobre a altura de plantas em ano onde houve estresse hídrico, o que não ocorreu neste trabalho. Em Castro (Tabela 3), no entanto, a aplicação antecipada de $120 \mathrm{~kg}$ há $^{-1}$ de $\mathrm{N}$ proporcionou menores alturas de planta e espiga quando comparado com a recomendação usual de aplicação na semeadura e cobertura.

A adubação da aveia com N não proporcionou aumento nos teores de $\mathrm{N}$ na folha índice. Entre as épocas de aplicação no milho, também não houve diferença quanto ao teor na folha. Somente a ausência adubação nitrogenada proporcionou os menores teores (Tabela 3 ).

\section{CONCLUSÕES}

A aplicação de $30 \mathrm{~kg}$ ha' ${ }^{1}$ de $\mathrm{N}$ na semeadura da aveia não influencia o rendimento do milho cultivado em sucessão.

O rendimento de grãos de milho não é afetado pela aplicação antecipada do $\mathrm{N}$ normalmente utilizado em cobertura no milho.

\section{REFERÊNCIAS BIBLIOGRÁFICAS}

AITA, C., CERETTA, C.A., THOMAS, A.L., et al. Espécies de inverno como fonte de nitrogênio para o milho no sistema de cultivo mínimo e feijão em plantio direto. R bras Ci Solo, Campinas, v.18, p.101-108, 1994.

BALlOTA, E.L., ANDRADE, D.S., COLOZZI FILHO, A. Avaliações microbiológicas em sistemas de preparo do solo e sucessão de culturas, m: CONGRESSO BRASILEIRO PLANTIO DIRETO PARA UMA AGRICULTURA SUSTENTÁVEL, 1996, Ponta Grossa, PR. Resumos expandidos... Ponta Grossa, IAPAR, 1996. v. 1. p.9-11.

CATTELAN, A.J., VIDOR, C. Sistemas de culturas e a população microbiana do solo. R bras Ci Solo, Campinas, v.14, p.125-132,1990.
CERETTA, C.A. Curso de atualização em recomendação de adubação e calagem: ênfase em plantio direto. Santa Maria, UFSM, 1997. Manejo da adubação nitrogenada na sucessão aveia/milho, no sistema plantio direto: p.111-124.

ESCOSTEGUY, P.A.V., RIZZARDI, M.A., ARGENTA, G. Doses e épocas de aplicação de nitrogênio em cobertura na cultura do milho em duas épocas de semeadura. $\mathbf{R}$ bras $\mathbf{C i}$ Solo, Campinas, v.21, p.71-77,1997.

HOLTZ, G.P. Dinâmica da decomposição da palhada e da distribuição do carbono, nitrogênio e fósforo numa rotação de culturas sob plantio direto na região de Carambei - PR. Curitiba, PR, 1995. 129p. Dissertação (Mestrado em Ciência do Solo) - Curso de Pós-graduação em Agronomia, Universidade Federal do Paraná, 1995.

IRITANI, W.M., ARNOLD, C.Y. Nitrogen release of vegetable crop residues during incubation as relatede to their chemical composition. Soil Science, Baltimore, v.89, p.74-82, 1960

JANSEN, H.H., KUCEY, R.M.N. Carbon, nitrogen and sulfur mineralization ofcrop residues as influenced by crop species and nutrient regime. Plant and sou, The Hague, v. 106, p.3541,1988 .

MACHADO, J.A. Efeito dos sistemas de cultivo reduzido convencional na alteração de algumas propriedades físicas e químicas do solo. Santa Maria, RS, 1976. 129p. Tese (Livre docência)- Universidade Federal de Santa Maria, 1976. 
MELGAR, RJ., SMITH, T.J., CRAVO, M.S., et al. Doses e épocas de aplicação de fertilizante nitrogenado para milho em latossolo da Amazónia Central. R bras Ci Solo, Campinas, v.15,p.289-296,1991

PARRA, M.S. Dinâmica de matéria orgânica e de nutrientes num latossolo roxo distrófico, submetido aos sistemas de plantio convencional e direto e a diferentes sucessões de cultura. Viçosa - MG, 1986. 94p. Dissertação (Mestrado em Solos) - Curso de Pós-graduação em Agronomia, Universidade Federal de Viçosa, 1986.

RAU, B.V. Fertilidade do solo e adubação. Piracicaba, São Paulo: CERES, POTAFOS, 1992. 343p.

SÁ, J.C.M. Manejo da fertilidade do solo no plantio direto. Castro: Fundação ABC, 1993.96p.

SÁ, J.C.M. Nitrogênio: influência da rotação de culturas e resposta da cultura do milho em solos sob plantio direto. In: CURSO SOBRE MANEJO DO SOLO NO SISTEMA PlANTIO DIRETO, 1995. Castro, PR. Anais... Castro ; Fundação ABC, 1995. 337p. p.213-227.

SÁ, J.C.M. Manejo de nitrogênio na cultura de milho no sistema plantio direto. Passo Fundo : Aldeia Norte, 1996, $23 \mathrm{p}$.

TEIXEIRA, L.A.J., TESTA, V.M., MBELNICZUK, J. Nitrogênio do solo, nutrição e rendimento de milho afetados por sistemas de cultura. R bras Ci Solo, Campinas, v.18, p.207-214, 1994.

SANGOI, L., ALMEIDA, M.L. Doses e épocas de aplicação de nitrogênio para a cultura do milho num solo com alto teor de matéria orgânica. Pesq Agropec bras, Brasília, v.29, n. 1, p.13-24,1994.

Ciência Rural, v. 30, n. 4, 2000. 